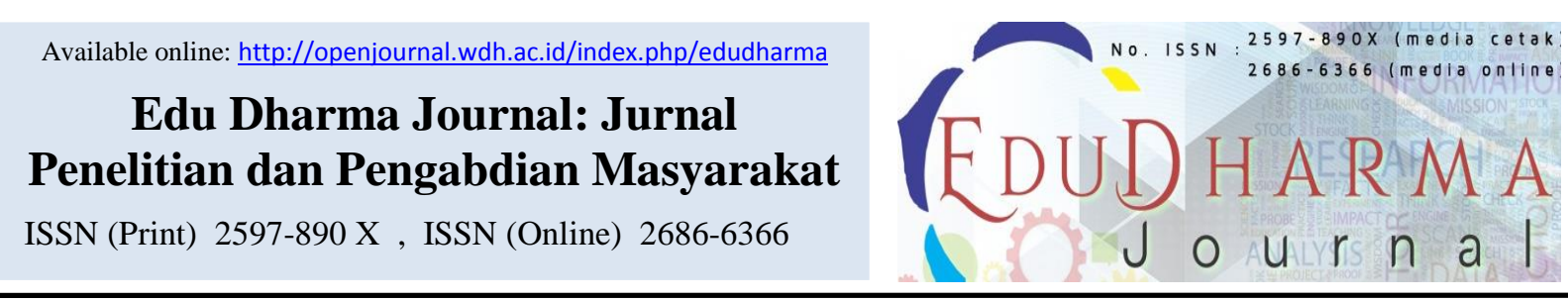

\title{
PENERAPAN TEKNIK ENDORPHIN TERHADAP NYERI KALA I PERSALINAN
}

Junaida Rahmi ${ }^{1}$, Riris Andriati ${ }^{2}$, Siti Novy Romlah ${ }^{3}$, Fitri Nur Annisa ${ }^{4}$, Diah Ayu Septiana ${ }^{5}$ STIKes Widya Dharma Husada Tangerang, 15417 Indonesia

\begin{tabular}{|c|c|}
\hline ARTICLE INFORMATION & $\begin{array}{llllllll}A & B & S & T & R & A & C & T\end{array}$ \\
\hline $\begin{array}{l}\text { *Corresponding Author } \\
\text { Junaida Rahmi } \\
\text { E-mail: } \\
\text { rahmijunaida @ gmail.com }\end{array}$ & $\begin{array}{l}\text { Labor pain is a natural thing that will serve every woman before the birth } \\
\text { process, labor pain can occur due to strong contractions that function as a } \\
\text { decrease in the baby's head and body. Labor pain causes a sense of discomfort } \\
\text { and anxiety which is presented to the mother in labor. Overcoming labor pain can } \\
\text { be done with pharmacological methods, namely analgesic and non- }\end{array}$ \\
\hline $\begin{array}{l}\text { Keywords: } \\
\text { Endorphin_1 } \\
\text { Technique_2 } \\
\text { Pain_3 } \\
\text { Labor_4 } \\
\text { First Stage_5 }\end{array}$ & $\begin{array}{l}\text { out 'The Effect of Endorphin Techniques on Labor Pain in the First Stage'. This } \\
\text { type of search uses the literature study method by collecting the data obtained } \\
\text { ( } n=955) \text {, analyzing, structured evaluation, and classification so as to get a } \\
\text { reference to the literature study. The results of the study found the Endorphin } \\
\text { Technique ( } n=5 \text { ) journal journals. The Endorphin Technique are very effective } \\
\text { in reducing labor pain and helping to accelerate the lowering of the baby's head } \\
\text { in laboring mothers so as to provide comfort to the mother before labor It is } \\
\text { hoped that health workers apply in midwifery care and provide health education } \\
\text { to mothers who give birth that the Endorphin Technique methods that can reduce } \\
\text { pain during the labor process. }\end{array}$ \\
\hline \multirow[t]{3}{*}{$\begin{array}{l}\text { Kata Kunci: } \\
\text { Teknik_1 } \\
\text { Endorphin_2 } \\
\text { Nyeri_3 } \\
\text { Persalinan_4 } \\
\text { Kala I_5 }\end{array}$} & $\begin{array}{l}\text { A B S T R A K } \\
\text { Nyeri persalinan merupakan hal wajar yang akan dialami oleh setiap wanita } \\
\text { menjelang proses persalinan, nyeri persalinan bisa terjadi karena adanya kontraksi } \\
\text { kuat yang berfungsi sebagai penurunan kepala dan badan bayi. Nyeri persalinan } \\
\text { menimbulkan rasa ketidaknyamanan serta rasa cemas yang dialami pada ibu } \\
\text { bersalin. Mengatasi nyeri persalinan dapat dilakukan dengan metode farmakologi } \\
\text { yaitu analgesic dan non farmakologi yaitu Teknik Endorphin. Tujuan Penelitian } \\
\text { Mengetahui 'Penerapan Teknik Endorphin Terhadap Nyeri Persalinan Kala I'. } \\
\text { Jenis penelitian yang menggunakan metode study literatur review dengan } \\
\text { mengumpulkan data yang diperoleh (n=955), telaah, evaluasi terstruktur, dan } \\
\text { pengklasifikasian sehingga mendapatkan kesimpulan mengenai studi literatur. } \\
\text { Hasil penelitian ditemukan Teknik Endorphin (n=5) jurnal. Teknik Endorphin } \\
\text { sangat efektif dalam mengurangi rasa nyeri persalinan dan membantu } \\
\text { mempercepat penurunan kepala bayi pada ibu bersalin sehingga memberikan rasa } \\
\text { nyaman kepada ibu bersalin menjelang proses persalinan. Diharapkan untuk } \\
\text { tenaga kesehatan menerapkan dalam asuhan kebidanan serta memberi pendidikan } \\
\text { kesehatan pada ibu bersalin bahwa Teknik Endorphin merupakan metode yang } \\
\text { dapat mengurangi rasa nyeri pada saat proses persalinan. }\end{array}$ \\
\hline & This is an open access article under the CC-BY-NC-SA license. \\
\hline & (C) 2020 Some rights reserved \\
\hline
\end{tabular}


PENDAHULUAN

Proses alamiah berakhirnya sebuah kehamilan yang mencapai usia aterm atau 37 - 40 minggu merupakan kondisi yang sangat dinanti yaitu proses persalinan. Pada kondisi ini hampir setiap wanita akan merasakan ketegangan dan kebahagian. Beberapa faktor yang menyebabkan hal ini terjadi diantaranya faktor psikologis yaitu rasa cemas, kesakitan saat kontraksi atau nyeri. Rasa nyeri dalam persalinan merupakan salah satu rasa nyeri yang paling intensif dialami ibu (Indrayani, 2013 dalam Rina dan Fariya 2020).

Rasa nyeri pada kehamilan dan persalinan diarikan sebagi sebuah "sinyal" untuk memberitahukan kepada ibu bahwa dirinya telah memasuki tahap proses persalinan. Nyeri merupakan mekanisme protektif bagi tubuh dan menyebabkan individu bereaksi untuk menghilangkan rangsang nyeri tersebut. Kontraksi inilah yang menimbulkan rasa sakit pada pinggang, daerah perut dan menjalar kearah paha (Lailiyana, dkk., 2012 dalam Rina dan Fariya 2020)

Untuk mengatasi nyeri persalinan dapat dilakukan dengan metode farmakologis dan nonfarmakologis. Metode farmakologis bisa berupa pemberian obat obatan sedangkan Metode nonfarmakologis yaitu dengan menggunakan Teknik Endhorpin.
Salah satu cara penatalaksanaan nonfarmakologis untuk mengurangi nyeri persalinan dengan endorphin massage. Endorphin Massage merupakan sebuah terapi sentuhan/pijatan ringan yang cukup penting diberikan pada wanita hamil, di waktu menjelang hingga saatnya melahirkan. Hal ini disebabkan karena pijatan merangsang tubuh untuk melepaskan senyawa Endorphin yang merupakan pereda rasa sakit dan dapat menciptakan perasaan nyaman (Kuswandi, 2012 dalam Sutani, dkk., 2018).

Selama ini endhorpin sudah dikenal sebagai zat yang banyak manfaatnya. Beberapa diantaranya adalah mengatur produksi hormon pertumbuhan dan seks, mengendalikan rasa nyeri serta sakit yang menetap, mengendalikan perasaan stress, serta meningkatkan sistem kekebalan tubuh. Endorphin dalam tubuh bias dipicu munculnya melalui berbagai kegiatan, seperti pernapasan yang dalam dan relaksasi, serta meditasi (Kuswandi, 2011 dalam Iin, dkk., 2011).

Berdasarkan uraian tersebut, peneliti tertarik untuk melakukan kajian studi literatur "Penerapan Teknik Endorphin Terhadap Nyeri Kala I Persalinan”. 


\section{METODE}

Jenis penelitian yang digunakan adalah deskriptif dengan metode Literature Review. Literature Review adalah metode penelitian literature yang sistematis, jelas dan komprehensif yang menggunakan metode pencarian eksplisit untuk mengumpulkan data yang ada untuk identifikasi, analisis dan evaluasi, dan melibatkan proses tinjauan kritis dalam pemilihan penelitian. menggunakan metode PRISMA dengan beberapa langkah yaitu 1) menyusun Background and Purpose (Latar Belakang dan tujuan), 2) Research Question, 3) Searching for the literature 4) Selection Criteria \& Practical Screen 5) Quality Checklist and Procedures 6) Data Extraction Strategy, 7) Data Synthesis Strategy.

Pada penelitian ini peneliti mengkaji permasalahan melalui jurnal penelitian yang berasal dari laporan hasil penelitian terdahulu "Teknik Endorphin AND nyeri persalinan AND kala I'. Scholar ( $\mathrm{n}=934)$, BASE (Bielefeld academic search engine) $(\mathrm{n}=9)$, Screening $(\mathrm{n}=886)$. Kriteria inklusi pada penelitian ini yaitu jurnal yang membahas tentang teknik endorphin dan rebozo terhadap nyeri persalinan kala I, besar sampel lebih dari 10 responden, jurnal diterbitkan dalam rentang waktu 10 tahun (2011-2021) serta jurnal nasional dan internasional dengan jumlah seluruh jurnal $(n=8) . \quad$ Kriteria eksklusi pada penelitian ini yaitu jurnal yang tidak dapat diakses dengan full text dan tidak sesuai dengan judul.

Bagan 1. Pencarian Jurnal Tahapan Literatur Review

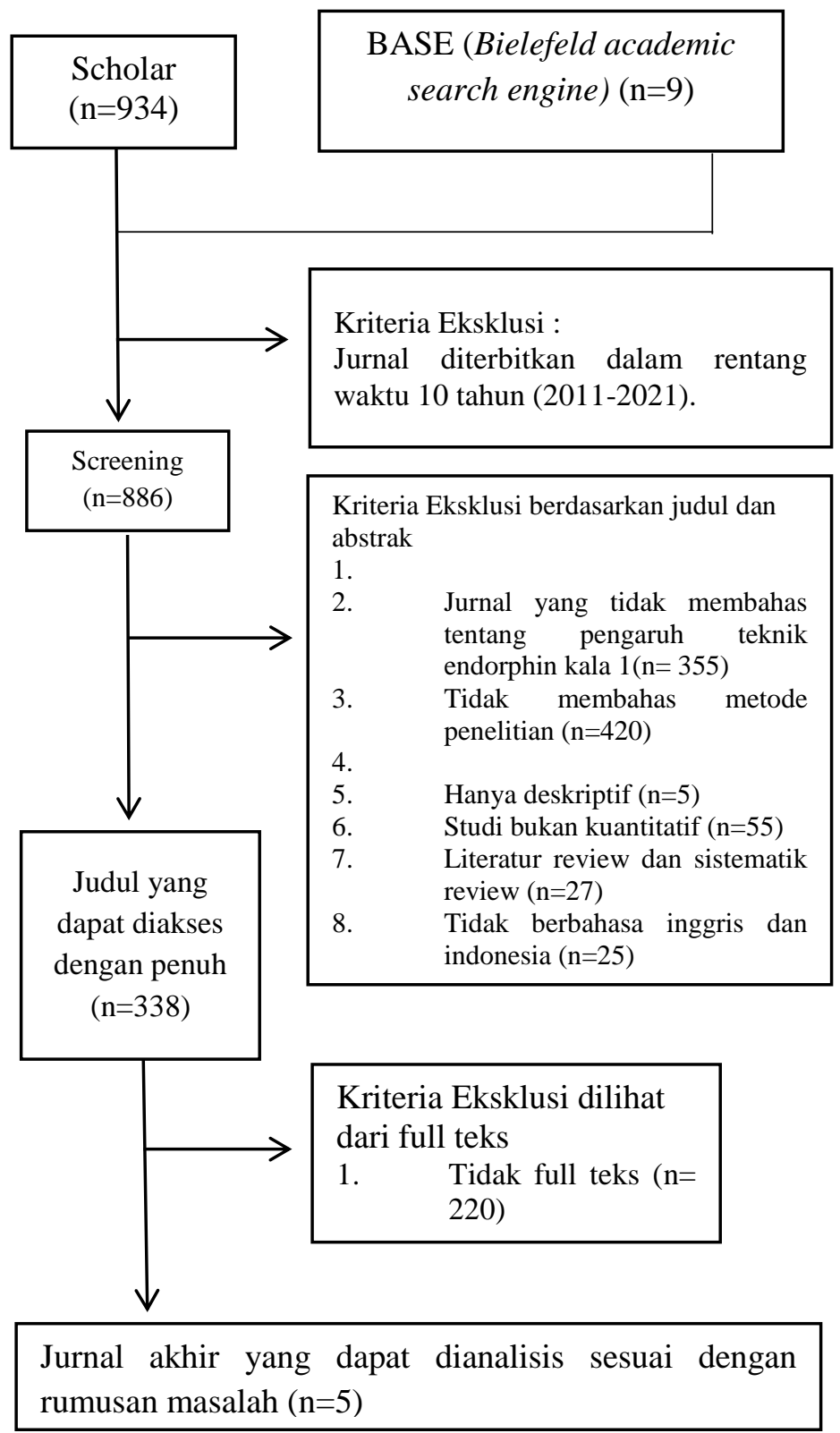




\section{HASIL}

Tabel 1. Hasil

\begin{tabular}{|c|c|c|c|}
\hline $\begin{array}{l}\text { Penulis dan } \\
\text { Tahun }\end{array}$ & $\begin{array}{l}\text { Desain Studi, Sampel, } \\
\text { Variabel, Instrumen, } \\
\text { Analisis }\end{array}$ & Hasil Faktor Analisis & Ringkasan Hasil \\
\hline $\begin{array}{l}\text { Nurun dan } \\
\text { Wiwin } 2020\end{array}$ & $\begin{array}{l}\text { Desain : purposive } \\
\text { sampling, Sampel : } 24 \\
\text { pasien, Variabel : pre and } \\
\text { post test design }\end{array}$ & $\begin{array}{l}\text { Berdasarkan penelitian skor sebelum } \\
\text { diberikan endorphin massage yaitu } \\
8,375 \text { dan setelah diberikan menurun } \\
\text { menjadi } 5,16 \text { sehingga rata-rata skor } \\
3,16\end{array}$ & $\begin{array}{l}\text { Sesudah diberikan endorphin } \\
\text { massage menunjukan bahwa } \\
\text { endorphin massage memiliki } \\
\text { efek penurunan intensitas } \\
\text { nyeri yang bermakna pada } \\
\text { ibu inpartu kala I fase aktif }\end{array}$ \\
\hline $\begin{array}{l}\text { Antik, dkk., } \\
2017\end{array}$ & 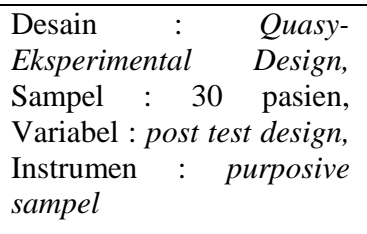 & $\begin{array}{l}\text { Dari } 30 \text { responden yang melakukan } \\
\text { endorphin message } 23 \text { responden } \\
\text { menunjukan respon baik setelah } \\
\text { diberikan endorphin massage }\end{array}$ & $\begin{array}{l}\text { Dari } 30 \text { responden yang } \\
\text { melakukan } \quad \text { endorphin } \\
\text { message } 23 \text { responden } \\
\text { menunjukan respon baik } \\
\text { setelah diberikan endorphin } \\
\text { massage }\end{array}$ \\
\hline $\begin{array}{l}\text { Mercy dan Sela } \\
2019\end{array}$ & $\begin{array}{l}\text { Desain : Pre eksperimen } \\
\text { Design, Sampel : } 30 \\
\text { pasien, Variabel : pre and } \\
\text { post test design, Instrumen } \\
\text { : purposive sampling }\end{array}$ & $\begin{array}{l}\text { Berdasarkan hasil observasi sebelum } \\
\text { diberikan Berdasarkan hasil observasi } \\
\text { sebelum diberikan endorphin message } \\
\text { terdapat } 11 \text { ibu bersalin }(36,7 \%) \text { yang } \\
\text { mengalami nyeri sedang dan } 19 \text { ibu } \\
\text { bersalin }(63,3 \%) \text { nyeri berat dan } \\
\text { sesudah dikakukan endorphin message } \\
\text { terdapat } 8 \text { ibu besalin }(26,7 \%) \text { yang } \\
\text { mempunyai nyeri ringan dan } 22 \text { ibu } \\
\text { bersalin ( } 73,3 \%) \text { yang mempunyai } \\
\text { nyeri sedang. }\end{array}$ & $\begin{array}{l}\text { Hasil yang didapat bahwa } \\
\text { pemberian endorphin } \\
\text { message Dapat menurunkan } \\
\text { ringkasan hasil nyeri } \\
\text { persalinan pada ibu bersalin } \\
\text { dan membuat lebih rileks }\end{array}$ \\
\hline Iin, dkk., 2011 & $\begin{array}{l}\text { Desain : Kuantitatif Quasy } \\
\text { Eksperimental Design, } \\
\text { Sampel : } 30 \text { pasien, } \\
\text { Variabel : post test only, } \\
\text { Instrumen : kuesioner }\end{array}$ & $\begin{array}{l}\text { rata-rata skala nyeri pada responden } \\
\text { sebelum dilakukan massage } 12,31 \text { dan } \\
\text { sesudah dilakukan massage skala nyeri } \\
\text { rata-rata } 4,69\end{array}$ & $\begin{array}{l}\text { Adanya pengaruh endorphin } \\
\text { massage terhadap intenstas } \\
\text { nyeri kala I persalinan }\end{array}$ \\
\hline $\begin{array}{ll}\text { Fitriana, } & \text { Nop } \\
2017 & \end{array}$ & $\begin{array}{l}\text { Desain }: \text { Quasy } \\
\text { Eksperimental Sampel : } 30 \\
\text { pasien, Variabel : pre and } \\
\text { post test, Instrumen : uji-t }\end{array}$ & $\begin{array}{l}\text { Sebelum diberikan Endorphin } \\
\text { massage rata-rata nilai nyeri yaitu } 7,20 \\
\text { dan nilai rata-rata sesudah diberikan } \\
\text { endorphin massage adalah } 6,73 \text {. }\end{array}$ & $\begin{array}{l}\text { Dari hasil penelitian tersebut } \\
\text { terdapat bahwa adanya angka } \\
\text { penurunan nyeri pada ibu } \\
\text { bersalin kala I }\end{array}$ \\
\hline
\end{tabular}

\section{PEMBAHASAN}

Dari hasil pencarian penelitian dari google scholar $(n=934)$ base $(n=9)$ dan dilakukan screening $(\mathrm{n}=886)$ sehingga diperoleh 5 jurnal. pijat endorphin dengan hasil endorphin memiliki efektivitas dalam mengurangi nyeri persalinan. Dari hasil penelitian (Nurun dan Wiwin 2020) dapat diketahui bahwa nilai rata-rata nyeri pada ibu bersalin sebelum diberikan endorphin massage yaitu 8,375 dan rata-rata nyeri menurun setelah diberikan endorphin massage menjadi 5,16 sehingga dapat disimpulkan bahwa teknik endorphin ini memiliki efektivitas dalam menurunkan nyeri, sama seperti penelitian yang dilakukan oleh (Antik, dkk., 2017) sebanyak 30 
responden yang diberikan endorphin massage 23 diantaranya memberikan efek yang baik setelah diberikan teknik endorphin massage, sejalan juga dengan penelitian yang dilakukan oleh (Fitriana, Nopi 2017) sebelum diberikan endorphin massage nilai rata-rata nyeri 7,20 dan nyeri berkurang menjadi 6,73 sehingga dapat diketahui bahwa teknik ini mampu dalam menurunkan nyeri pada persalinan kala I.

Endorphin Message merupakan sebuah terapi sentuhan/pijatan ringan yang cukup penting diberikan pada wanita hamil, di waktu menjelang hingga saatnya melahirkan. Hal ini disebabkan karena pijatan merangsang tubuh untuk melepaskan senyawa Endorphin yang merupakan Pereda rasa sakit dan dapat menciptakan perasaan nyaman (Kuswandi, 2012 dalam Sutrani, dkk., 2018).

Menurut peneliti sesuai dengan hasil yang didapat tentang teknik endorphin massage ternyata teknik tersebut memiliki efektivitas menurunkan intensitas nyeri kala I pada ibu bersalin dengan cara sentuhan halus pada tubuh ibu yang membuat ibu merasa lebih nyaman serta rileks dalam menjalani proses persalinan dimana hal tersebut yang dapat membuat ibu merasakan penurunan dalam merasakan nyeri sehingga ibu bisa menyambut proses persalinan dengan tenang.

\section{KESIMPULAN}

Berdasarkan hasil penelitian dari beberapa sumber yang telah dikumpulkan oleh penulis mengenai "Penerapan Teknik Endorphin Terhadap Nyeri Kala I Persalinan" penulis menyimpulkan bahwa Berdasarkan hasil temuan penelitian dari google scholar $(n=934)$ base $(\mathrm{n}=9)$ dan dilakukan screening $(\mathrm{n}=886)$ sehingga diperoleh 5 jurnal. Penerapan Teknik Endorphin Massage terbukti memberikan efektivitas yang cukup baik dalam mengurangi rasa nyeri pada persalinan, rasa ketidaknyamanan, serta kecemasan pada ibu bersalin menjelang proses persalinan dengan menggunakan teknik sentuhan ringan yang diberikan kepada ibu bersalin menjelang proses persalinan.

\section{DAFTAR PUSTAKA}

Anik, 2020. Effect Of Application Rebozo Techniques On Pain Intensity And Anxiety Levels To the Mother Gives Birth $1^{\text {st }}$ Phase Of Active.

Dwi, R., Purnama, F., Wulan, N., Andriati, R. (2020). Panduan KTI Study Literatur Review dan Systematic review. Stikes WDH Tangerang, (1-45).

Fitriana dan Nopi 2017. Pengaruh Pijat Endorphin (Endorphin Massage) Terhadap Intensitas Nyeri Kala I Pada Ibu Primipara 
Iin, Melyana, Novita 2011. Pengaruh Endorphin Massage Terhadap Intensitas Nyeri Kala I Persalinan Normal Ibu Primipara Di BPS S Dan B Demak Tahun 2011.

Melia dan Devi 2018. Perbedaan Efektivitas Endorphin Massage Dengan relaksasi Hypnobirthing Terhadap Penurunan Nyeri Persalinan Kala I Fase Aktif di Rumah Bersalin Citra Palembang.

Mercy dan Sela 2020. Pengaruh Endorphin Massage Terhadap Intensitas Nyeri Persalinan Kala I Fase Aktif Dilatasi Maksimal.

Nursalam. (2020). Pedoman Penyusunan Literatur dn Systematik Review. Surabaya, (1-28).

Nurun da wiwit 2020. Pengaruh Endorphin Massage Terhadap Intensitas Nyeri Pada Ibu Bersalin

Rina dan Fariya 2020. Efektifitas Pernapasan Dalam Dan Endorphin Massage Terhadap Intensitas Nyeri Kala I Fase Aktif Persalinan Di Puskesmas Kecamatan Tanah Abang.

Sutrani, Sumarni, Mega, 2018. Pengaruh Endorphin Massage Terhadap Percepatan Persalinan Kala I Di Puskesmas Ajangale Kabupaten Bone Tahun 2018. 